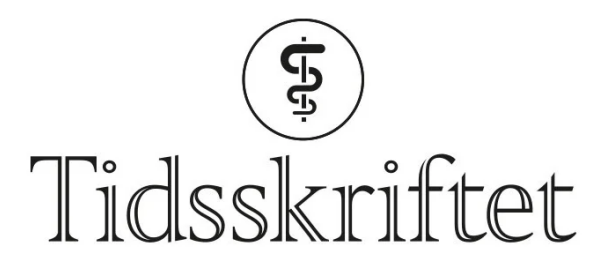

DEN NORSKE LEGEFORENING

\title{
Når er en potensiell organdonor død?
}

\author{
KRONIKK
}

\section{PAAL H.H. LINDENSKOV}

paal.lindenskov@gmail.com

Paal HH Lindenskov er spesialist i anestesiologi og barnesykdommer og dr.med. Han arbeider som overlege på Oslo universitetssykehus, Rikshospitalet, med særlig ansvar for barneanestesiologi. Forfatteren har fylt ut ICMJE-skjemaet og oppgir ingen interessekonflikter.

\section{J $\varnothing R G E N$ DAHLBERG}

Jørgen Dahlberg er spesialist i anestesiologi, jurist med advokatbevilling og overlege i anestesi på Akershus universitetssykehus. Han har også en deltids forskerstilling ved Senter for medisinsk etikk, Universitetet i Oslo. Han er medforfatter av metodevurderingen «Organdonasjon med bruk av normoterm regional perfusjon hos pasienter som dør av hjerte- og åndedrettsstans når livsforlengende behandling avsluttes».

Forfatteren har fylt ut ICMJE-skjemaet og oppgir ingen interessekonflikter.

\section{Beslutningsforum for nye metoder har godkjent en ny prosedyre hvor organdonasjon kan skje etter at donors sirkulasjon har stanset. Hva ligger bak denne godkjenningen, som vi mener er riktig og godt begrunnet?}




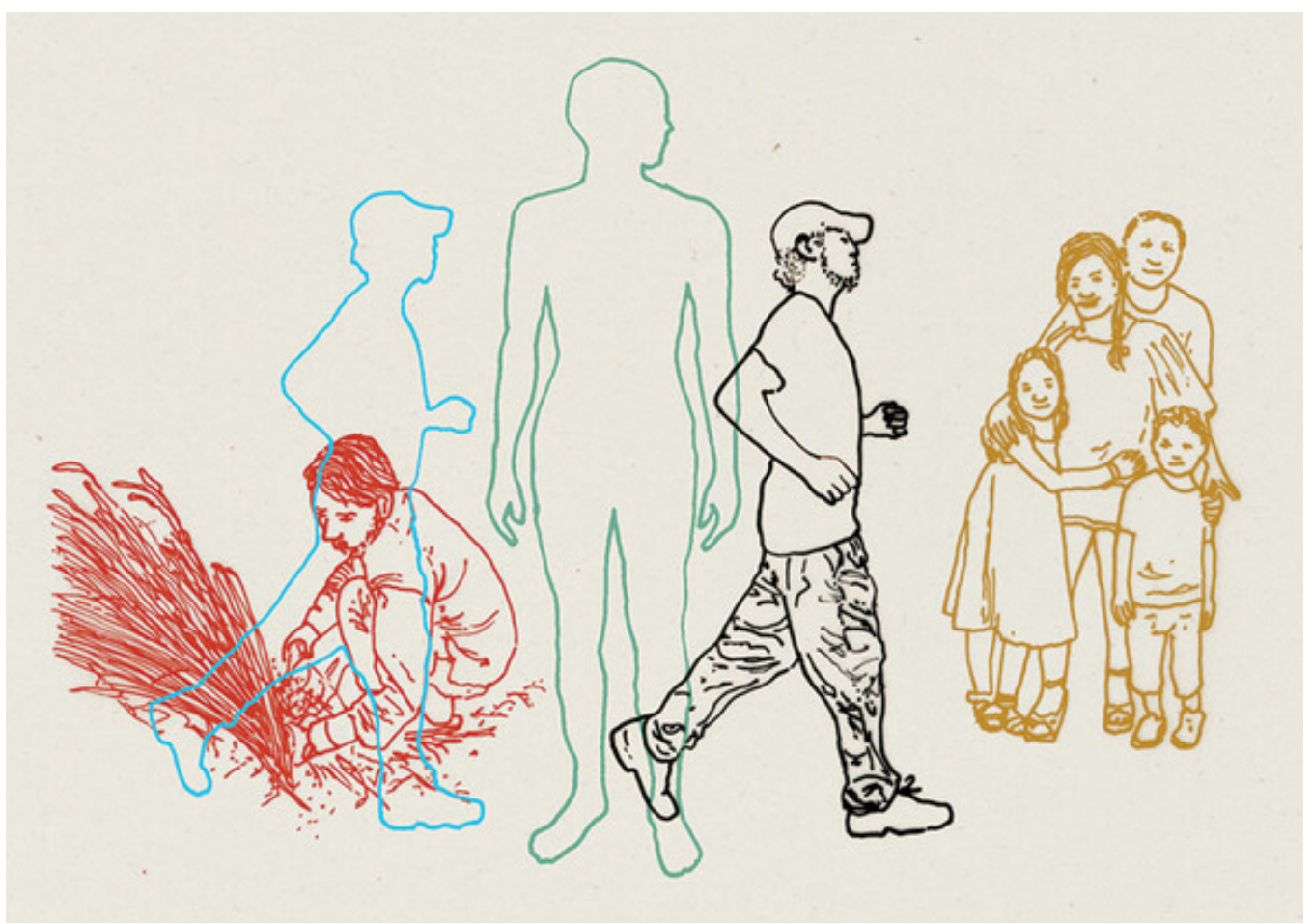

Illustrasjon: Roderick Mills / Heart Agency

Spørsmålet om etablering av kontrollert donasjon etter sirkulatorisk død (på engelsk: controlled donation after circulatory death, $\mathrm{CDCD}$ ) ved siden av den eksisterende metoden donasjon etter hjernedød (på engelsk: donation after brain death, DBD) ble tatt opp for mer enn ti år siden (1). Siden den gang har metoden vært debattert, diskutert, søkt utredet i pilotstudier og vært gjenstand for en fullstendig metodevurdering før den endelig har blitt iverksatt (2). Fortsatt er det mange som stiller spørsmål ved hva metoden faktisk innebærer og om det er riktig å innføre den i Norge.

Vi vil i denne kronikken belyse hva metoden faktisk innebærer og klargjøre noen av de temaene som synes å ha skapt størst utfordring blant våre kolleger, særlig spørsmålet om dødsdefinisjonens premisser og juridiske grunnlag.

\section{Organtransplantasjonens start}

Historien om organtransplantasjoner består av tre faser: utvikling av kirurgiske teknikker for å sy sammen små blodårer, utvikling av immunsuppressive legemidler slik at både mottager og det transplanterte organ overlever, og definisjon av dødskriteriet ved transplantasjon fra døde givere.

«En av de største utfordringene ved organdonasjon har vart angivelsen av når døden inntrer»

Så tidlig som 1911 utførte finnmarkingen Ragnvald Ingebretsen (1882-1975) under studieopphold ved Rockefeller Instituttet i New York nyretransplantasjon på katter (3). I 1954 utførte Murray (1919-2012) og medarbeidere i Boston den første vellykkete humane nyretransplantasjonen (3). På denne tiden var såkalt hjertedød enerådende som dødskriterium, og det forelå liten kunnskap om muligheten til å hente ut brukbare organer fra død donor. Transplantasjoner ble derfor i praksis kun utført fra levende donor og da kun som nyretransplantasjoner. Det medisinske miljøet ved Harvard Medical School i Boston hadde imidlertid begynt å jobbe med kriterier for hjernedød på 6o-tallet. Disse kriteriene ble publisert i 1968 (4). Denne nye dødsdefinisjonen muliggjorde 
transplantasjon også av andre organer enn nyrer. Verdens første hjertetransplantasjon mennesker imellom ble på dette grunnlaget gjennomført av Christiaan Barnard (19222001) i Sør-Afrika i 1967.

For å unngå avstøtning ved at mottagers immunapparat ikke gjenkjenner transplantert organ som eget vev, brukte man i denne tidlige perioden så sterk immunsuppresjon at pasientene ofte døde av infeksjon. Det tilkom imidlertid et sceneskifte i 1972 da man lyktes med å utvikle mer selektiv immunsuppresjon ved bruk av det biologiske stoffet ciklosporin - utvunnet fra en sopp på Hardangervidda (3).

\section{Særlig om utfordringen rundt dødsbegrepet}

En av de største utfordringene ved organdonasjon har vært angivelsen av når døden inntrer. Spørsmålet har vært utfordrende da donasjon fra død giver forutsetter at organer hentes ut mens de fortsatt er vitale samtidig som inngrepet åpenbart ikke kan skje før donor er død. Så hva er død?

Døden inntrer ikke øyeblikkelig i en biologisk kontekst, men snarere som en utfasing av et univers av biokjemiske prosesser og cellulær aktivitet. Når hjertet stanser, og sirkulasjonen oppheves, vil alle kroppens celler i løpet av minutter lide av energisvikt, og de komplekse cellulære og biokjemiske prosessene som er vårt biologiske liv, vil opphøre.

\section{«Det bør bemerkes at kontrollert donasjon etter sirkulatorisk død ikke er en norsk oppfinnelse»}

Ved hjernedød opphører sirkulasjonen isolert for hjernen. Man kan få en sterk indikasjon på at hjernen er død ved forskjellige kliniske tester, men den endelige definisjonen for hjernedød i Norge er påvisning av opphørt blodsirkulasjon, hvilket utføres med en røntgenkontrastundersøkelse (5). Avdøde vil på dette tidspunktet fortsatt ha blodtilførsel til kroppen opprettholdt av intensivbehandling, men en hjerne uten sirkulasjon og funksjon. Denne dødsdefinisjonen har banet vei for bedre organpreservering samt at det har blitt teknisk mulig å transplantere hjerte og lunger.

Avhengig av hvilket organ som transplanteres, kan disse ivaretas fra levende eller døde. Ved å avkjøle de fridissekerte organene reduseres stoffskifte og energiomsetning til et minimum slik at de kan preserves i inntil 24 timer før de blir resirkulert ved reimplantasjon i mottagers kropp. Ethvert organ som fjernes etter inntrådt sirkulasjonsstans, vil innen relativt kort tid kunne skades. Således er det ønskelig at organet tas ut mens sirkulasjonen er intakt og deretter nedkjøles raskt i fridissekert tilstand.

\section{Nærmere om de juridiske dilemmaer}

Som i mye annet har lovgivningen kommet i kjølvannet av den medisinske utviklingen på dette området. Da transplantasjonsvirksomhet begynte i Norge på slutten av 1950-tallet, var det derfor ingen egen lovregulering. Virksomheten ble drevet etter de generelle juridiske og medisinske retningslinjer. Dødsdefinisjonen var heller ikke spesifikt regulert, og død ble derfor stadfestet på den alminnelige måten, hvilket var opphør av sirkulasjon og respirasjon.

En komité, senere kjent som Andenæs-komitéen, ble nedsatt i 1969 for å utrede spørsmålet om lovgivning ved transplantasjon i Norge (ㅁ). Den gikk blant annet særlig inn på spørsmålet om dødsdefinisjon i sin behandling av organdonasjon fra død giver. Det ble vist til at nyere medisinsk kunnskap i stor grad hadde utvidet sin oppfatning av dødsdefinisjonen til å omfatte hjernedøde. Selve lovforslaget gikk imidlertid ikke i detalj 
på hvordan døden skulle stadfestes: «Etter komiteens mening er spørsmålet om tidspunktet for dødens inntreden et faglig spørsmål, som må avgjøres ut fra den innsikt og de undersøkelsesmetoder som til enhver tid er allment akseptert i medisinen. Dødsdefinisjonen egner seg ikke for regulering i lovs form» (므).

På denne bakgrunnen ble transplantasjonsloven vedtatt i 1973. Med hjemmel i loven ble det så utferdiget en forskrift om dødsdefinisjon i 1977 som i noe grundigere detalj definerte $\mathrm{d} ø \mathrm{~d}$ (7.). Forskriften inneholdt både den tradisjonelle dødsdefinisjonen, som viste til varig hjerte- og åndedrettstans, og den nye dødsdefinisjonen, som viste til total ødeleggelse av hjernefunksjon. Det er verdt å merke seg at det tradisjonelle dødskriteriet ble oppfattet som en alminnelig hovedregel, mens det nye hjernedødskriteriet kom til som en spesialbestemmelse.

\section{"I stor grad ser kritikken ut til å vare et resultat av}

\section{kommunikasjonssvikt vedrørende lansering av metoden»}

Utvikling på fagområdet førte til at man i Norge nedsatte et nytt utvalg som presenterte et nytt lovforslag i NOU 2011:21 - «Når døden tjener livet» (1). Stadfesting av død ved total ødeleggelse av hjernen var på dette tidspunktet langt på vei blitt det eneste dødskriteriet som ble brukt ved organtransplantasjon fra død donor i Norge. Utvalget viste imidlertid til at det igjen kunne bli aktuelt å hente organer fra donor hvor død ble stadfestet ved de tradisjonelle dødskriteriene med sirkulasjonsstans og viste blant annet til etableringen av et pilotprosjekt for organdonasjon etter sirkulatorisk $\mathrm{d} ø \mathrm{~d}$ ved Oslo universitetssykehus. Det ble pekt på at regelverket ikke måtte utgjøre noe hinder for at slik organdonasjon skulle kunne gjeninnføres, og at det tradisjonelle dødskriteriet fortsatt inngikk i lovforslaget. I Folkehelseinstituttets metodevurdering av kontrollert donasjon etter sirkulatorisk død ble det også spesifikt uttalt at «det er ikke identifisert noen juridiske hindringer» for å utføre organdonasjon etter sirkulatorisk død (ㄹ) .

\section{Hvor står vi i dag?}

Ringen ser ut til å være sluttet tilbake til de første transplantasjonene. Kontrollert donasjon etter sirkulatorisk død benyttes kun på pasienter med ubotelig hjerneskade som med intensivmedisinsk behandling ikke har vist tegn til bedring som kunne gi håp om overlevelse, og som antas å få sirkulasjonsstans innen go minutter etter at sirkulasjonsfremmende behandling og respiratorbehandling avvikles. Hvis så ikke skjer innenfor tidsfristen, vil ikke pasienten kvalifisere til å være donor og vil følge sin naturlige dødsprosess videre.

Hvis sirkulasjonen opphører innenfor denne tidsfristen, avventer man i ytterligere fem minutter for å utelukke at egensirkulasjonen gjenoppstår før man aktiverer et kunstig kretsløp via kanyler i lyskene. Denne prosessen tar ytterligere 5-10 minutter, slik at frist for gjenvunnet egensirkulasjon i praksis er nær et kvarter. Med oppblåst ballong $\mathrm{i}$ hovedpulsåren etablert via lysken blokkeres arteriell sirkulasjon over mellomgulvet. Slik preserveres organer som lever, nyrer og bukspyttkjertel, mens hjerte, lunger og hjerne er avskåret fra ekstern sirkulasjon. Distalt i aortaballongen finnes en trykkmåler slik at gjenetablert egensirkulasjon etter etablert regional reperfusjon abdominalt likevel vil kunne erkjennes.

Det er viktig å presisere at beslutningen om tilbaketrekning av nytteløs behandling ved kontrollert donasjon etter sirkulatorisk død skjer på samme vis som når man gir opp intensivbehandling - med tillegg av de formelle grep som gjøres ved enhver transplantasjon, det være seg i henhold til tradisjonelle hjernedødskriterier eller nytilkomne kriterier for donasjon ved sirkulatorisk død. For å hindre at beslutningen om tilbaketrekning skal være påvirket av at pasienten kan tjene som donor, skal aldri legen 
som stadfester døden, delta i uthenting av organer. Det er videre viktig å ha klart for seg at begrensning i eller tilbaketrekning av intensivbehandling er umiddelbar dødsårsak i rundt 80 prosent av tilfellene på en intensivavdeling $(\underline{8})$, underforstått at døden inntrer som en naturlig hendelse ved at livsforlengende behandling avvikles.

«Det ville vare beklagelig at en metode som vil bidra til at døden kommer livet til tjeneste, skulle havne i miskreditt på feilaktige premisser»

Det bør bemerkes at kontrollert donasjon etter sirkulatorisk død ikke er en norsk oppfinnelse. Denne metoden er i bruk i mange land, herunder et flertall av landene i EU, Canada og en rekke delstater i USA. Som ved kontrollert donasjon etter sirkulatorisk død etter hjernedød finnes det ulike variasjoner mellom ulike land. Den norske metoden har sånn sett trolig flest likhetstrekk med den franske metoden. Der ble organdonasjon etter sirkulatorisk død startet i 2006, og den någjeldende metoden har vært i bruk siden 2014.

\section{Hjertedød kan gi et nytt håp}

Det har vært noe kritikk rundt lanseringen av kontrollert donasjon etter sirkulatorisk død som en ny metode for å skaffe til veie organer fra døde til levende i Norge. Det er ingen grunn til å legge skjul på at enkelte kolleger har prinsipielle motforestillinger, men i stor grad ser kritikken ut til å være et resultat av kommunikasjonssvikt vedrørende lansering av metoden. Altså har metodens gode hensikt og entydige dødsdefinisjon etter vårt syn blitt underkommunisert.

Antall organtransplantasjoner fra avdøde med den etablerte metoden for organdonasjon etter hjernedød er cirka 120 per år. Utførte organdonasjoner etter sirkulatorisk død antas å $\emptyset$ ke det totale antallet transplantasjoner med 10-15\%. Vår støtte til bruk av kontrollert donasjon etter sirkulatorisk død baserer seg ikke på at antallet donororganer vil øke. Vi mener at begrepet hjerted $\varnothing \mathrm{d}$ anvendt ved kontrollert donasjon etter sirkulatorisk død virker minst like avklart og ukontroversielt som det etablerte hjernedødkriteriet. Videre konstaterer vi at sedvanlig praksis for avvikling av intensivbehandling ved uopprettelig håp om liv ligner mer på praksis ved kontrollert donasjon etter sirkulatorisk død enn ved hjernedød, og at hjertedød var den opprinnelige dødsdefinisjonen i transplantasjonsmedisinens historie. Således virker ringen sluttet nå.

Til sist vil vi fremheve at kontrollert donasjon etter sirkulatorisk død vil tilrettelegge for at personer som ønsker å donere organer etter sin død, kan få realisert sitt ønske om organdonasjon. Mange har tidligere vært forhindret i dette av rent formaljuridiske hensyn ettersom forutgående praksis bare har akseptert hjernedød som donasjonskriterium. Etter vårt syn vil metoden falle innenfor de eksisterende medisinsketiske rammer for forsvarlig donasjonspraksis og samtidig ivareta donors autonomi. Hjertedød kan slik bli et nytt håp ikke bare for den døende, men også for den døde.

\section{Avslutning}

Etiske problemstillinger rundt liv og død er i høyeste grad et offentlig anliggende. Et offentlig ordskifte om så vel de prinsipielle sider ved kontrollert donasjon etter sirkulatorisk død som praktisk gjennomføring av metoden er en forutsetning for forsvarlig praksis. Enhver transplantasjonspraksis må bygge på verdighet og entydige kriterier for død, slik at vi ikke sklir ut som «organprofitører». 
Hjernedødskriteriet er betryggende og vel etablert. Det gir seg imidlertid intuitivt at et menneske er like dødt når global sirkulasjon opphører, som når lokal sirkulasjon til hjernen er opphørt. Kriteriet for hjernedød er strengt tatt også mer teknologibasert med kontrastundersøkelse enn klinisk observert respirasjonsstans og tapt sirkulasjon målt i en arteriekanyle. Ved begge metoder har man likeverdige tilleggskriterier for å konstatere klinisk død. Det ville være beklagelig at en metode som vil kunne bidra til at døden kommer livet til tjeneste, skulle havne i miskreditt på feilaktige premisser. Respekt for livet må alltid stå høyest. Derfor bør en forlengelse av pasienters liv, slik man oppnår ved organtransplantasjon, trumfe $\mathrm{d} ø \mathrm{~d}$.

\section{REFERENCES}

1. NOU 2011: 21. Når døden tjener livet. DCD (Donation after cardiac death). https://www.regjeringen.no/no/dokumenter/nou-2011-21/id666923/?ch=10\#kap8-3-6

2. Giske L, Solberg B, Tranvåg E et al. Organdonasjon med bruk av normoterm regional perfusjon hos pasienter som dør av hjerte- og åndedrettsstans når livsforlengende behandling avsluttes. Oslo: Folkehelseinstituttet, 2019.

https://www.fhi.no/globalassets/dokumenterfiler/rapporter/2019/organdonasjon-med-bruk-avnormoterm-regional-perfusjon-mm-rapport-2019.pdf

3. Thorsby E. Norsk transplantasjonsmedisin gjennom 50 år. Tidsskr Nor Lægeforen 2006; 126:330510. [PubMed]

4. A definition of irreversible coma. Report of the Ad Hoc Committee of the Harvard Medical School to Examine the Definition of Brain Death. JAMA 1968; 205: 337-40. [PubMed][CrossRef]

5. FOR-2015-12-21-1813. Forskrift om dødsdefinisjon ved donasjon av organer, celler og vev $§ 3$. https://lovdata.no/dokument/SF/forskrift/2015-12-21-1813/\%C2\%A73\#\%C2\%A73

6. Ot.prp. nr 52 (1971-2). Om lov om transplantasjon, sykehus-obduksjon, avgivelse av lik, m.m. https://www.stortinget.no/nn/Saker-og-publikasjonar/Stortingsforhandlingar/Lesevisning/? $\mathrm{p}=1971^{-}$ 72\&paid=4\&wid=b\&psid=DIVL285\&pgid=b_0447

7. FOR-1977-06-10-2. Forskrifter om dødsdefinisjonen i relasjon til lov om transplantasjon, sykehusobduksjon og avgivelse av lik m.m.https://lovdata.no/dokument/SFO/forskrift/1977-o6-10-2? $\mathrm{q}=$ forskrift $\% 200 \mathrm{~m} \% 20 \mathrm{~d} \% \mathrm{C} \% \mathrm{~B} 8 \mathrm{dsdefinisjon}$

8. Avidan A, Sprung CL, Schefold JC et al. Variations in end-of-life practices in intensive care units worldwide (Ethicus-2): a prospective observational study. Lancet Respir Med 2021; 9: 1101-10. [PubMed][CrossRef]

Publisert: 28. februar 2022. Tidsskr Nor Legeforen. DOI: 10.4045/tidsskr.21.0792

Mottatt 17.12.2021, godkjent 5.1.2022.

(C) Tidsskrift for Den norske legeforening 2023. Lastet ned fra tidsskriftet.no 26. april 2023. 